This manuscript is a preprint and has been submitted for publication in Scientometrics. Please note that, despite having undergone peerreview, the manuscript has yet to be formally accepted for publication. Subsequent versions of this manuscript may have slightly different content. If accepted, the final version of this manuscript will be available via the 'Peer-reviewed Publication DOl' link on the right-hand side of this webpage. Please feel free to contact any of the authors; we welcome feedback. $12^{\text {th }}$ November 2020. Version 1.

The Influence of Dust Levels on Atmospheric Carbon Dioxide and Global Temperature

David Edmund Allen, Department of Mathematics and Statistics, University of Sydney and School of Business and Law, Edith Cowan University, and Department of Finance, Asia University.

Danail Sandakchiev, Faculty of Economics and Business Administration, Sofia University "St. Kliment Ohridski”, Bulgaria.

Vincent Hooper, School of Economics and Management, Xiamen University, Malaysia.

Ivan Ivanov, Faculty of Economics and Business Administration, Sofia University "St. Kliment Ohridski", Bulgaria. 


\title{
The Influence of Dust Levels on Atmospheric Carbon Dioxide and Global Temperature
}

\author{
David Edmund Allen, Department of Mathematics and Statistics, University of \\ Sydney and School of Business and Law, Edith Cowan University, and \\ Department of Finance, Asia University.
}

Danail Sandakchiev, Faculty of Economics and Business Administration, Sofia University “St. Kliment Ohridski”, Bulgaria.

Vincent Hooper, School of Economics and Management, Xiamen University, Malaysia.

Ivan Ivanov, Faculty of Economics and Business Administration, Sofia University "St. Kliment Ohridski", Bulgaria.

\begin{abstract}
The purpose of this paper is to examine the causality between DUST, CO2 and temperature for the Vostok ice core data series [Vostok Data Series], dating from 420000 years ago, and the EPICA C Dome data going back 800000 years. In addition, the time-varying volatility and coefficient of variation in the $\mathrm{CO} 2$, dust and temperature is examined, as well as their dynamic correlations and interactions. We find a clear link between atmospheric $\mathrm{C0} 2$ levels, dust and temperature, together with a bi-directional causality effects when applying both Granger Causality Tests (1969) and multi-directional Non-Linear analogues, i.e. Generalized Correlation. We apply both parametric and non-parametric statistical measures and testing. Linear interpolation with 100 years and 1000 years is applied to the three variables, in order to solve the problem of data points mismatch among them. The visualizations and descriptive statistics of the interpolated variables (using the two periods) show robustness in the results. The data analysis points out that variables are volatile, but their respective rolling mean and standard deviation remain stable. Additionally, 1000 years interpolated data suggests positive correlation between temperature and $\mathrm{CO} 2$, while dust is negatively correlated with both temperature and $\mathrm{CO} 2$.
\end{abstract}

The application of the non-parametric Generalized Measure of Correlation to our data sets, in a pairwise fashion suggested that $\mathrm{CO} 2$ better explains temperature than temperature does $\mathrm{CO} 2$, that temperature better explains dust than dust does temperature, and finally that $\mathrm{CO} 2$ better explains dust than vice -versa. The latter two pairs of relationships are negative.

The summary of the paper presents some avenues for further research, as well as some policy relevant suggestions.

November $12^{\mathrm{TH}} 2020$ 


\section{INTRODUCTION}

Dust and climate change is only recently drawing the attention of scientists. Our major contribution is applying non-linear causality tests to dust, $\mathrm{CO} 2$ and temperature, i.e. the General Correlation Method, that has never been implemented in climate research but better captures the interaction between parameters. The potential for global climate change has implications for the planet across all ecosystems. The authoritative consensus that humans are causing recent global warming is supported by $90-100 \%$ of publishing climate scientists [Cook et al, 2016]. Whilst it is not an objective of this paper to wade into the wider debate on whether climate change is man-made or not, we attempt to make some assertions based on stylized facts distilled from the Ice Core datasets, to add to a limited body of literature on the influence of dust upon the relationship between $\mathrm{CO} 2$ and temperature.

The major contribution of this paper is to apply non-linear causality tests on the Vostok Ice Core Dataset, as well as to examine the time varying nature of volatility of $\mathrm{CO} 2$ and temperature with regard to dust by using both parametric and non-parametric modelling techniques.

The potential for climate change is a major issue facing the world today. The majority of climate scientists acknowledge that there is a strong link between $\mathrm{CO} 2$ levels in the atmosphere and temperature. Generally, as $\mathrm{CO} 2$ levels rise, then global temperature rises. It is also acknowledged that the oceans absorb excess carbon dioxide becoming acidified, with increasing evidence that this is responsible for coral bleaching on the Great Barrier Reef, accompanied by damage to marine ecology. Most governments around the globe have placed emphasis upon reducing $\mathrm{CO} 2$ emissions, particularly that emanating from fossil fuels to limit temperature increases. Global temperature increases have the potential to melt the ice caps and increase sea levels, raising the specter of floods, plagues and further environmental damage through further climate change. The relationship between $\mathrm{C} 02$ and temperature is complex and causality links are possibly bi-directional, because as global sea temperatures rise, $\mathrm{CO} 2$ that was absorbed in the ocean is released into the atmosphere, raising temperature. This can lead to a very damaging feedback loop. There is a limit to the amount of CO2 the oceans can hold. In other words, C02 raises temperature, but then temperature raises $\mathrm{CO} 2$ levels and so on, until a downward cycle persists then $\mathrm{C} 02$ and temperature drop in tandem, with dust being an intervening factor as well as ocean absorption. It is possible to hypothesize that the upward trends and downward trend in $\mathrm{CO} 2$, temperature and dust are nonlinear or asymmetrical which can be supported by the outcome from the non-linear causality analysis. However, our analysis may provide hints on the direction of global C02 and temperature levels, within the context of current dust levels in the atmosphere.

Scientists have stressed in recent times that the CO2-Temperature is complicated by 
atmospheric dust levels. Indeed, they argue that the influence of dust on the Earth's climate is largely ignored and that depending upon the nature of the dust in terms of its particle size and chemical composition can have different effects upon global temperatures. In other words, dust can reflect sunlight in the atmosphere and have a cooling effect but black soot can absorb sunlight, thus increasing temperature. Thus from a climate change perspective there is 'good dust' and 'bad dust'.

Given the growing importance that dust may play in future climate modeling, remote sensing including satellite technology are increasingly attempting to capture dust in their data collection processes. Whilst this will undoubtedly improve our understanding of the impact of dust on climate, particularly at a regional level, our approach is to take a longer time framework spanning 1 million years to investigate the complex relationship between Dust, $\mathrm{CO} 2$ and temperature using time-series data collected from the ice caps in conjunction with state-of-the-art modeling techniques. In addition we examine the dynamic or time-varying nature of correlations and volatilities of $\mathrm{CO} 2$, Temperature and Dust.

This paper is organized as follows:

Section 2. covers a literature review, examining recent literature between $\mathrm{CO} 2$ and Temperature and Dust. Section 3, describes the data and presents some descriptive statistics including means, correlations, variances (volatilities). Section 3, presents this information in tables as well graphs. In addition, Section 3 explores the dynamic timeseries relationships between CO2, Temperature and Dust in terms of their correlations and volatilities. Section 4 describes the advanced time-series modeling and results. Section 5 summarizes and concludes our work, outlining directions for future research, as well as policy implications. Section 6 . Records the references and other supporting sources for this paper.

\section{LITERATURE REVIEW}

Kodra, Chatterjee and Ganguly (2011) explored the Granger Causality between global average observed time series of carbon dioxide and temperature:

Suppose $\mathrm{X}$ and $\mathrm{Y}$ form a bivariate time series given by the dynamic relationship: 


$$
\begin{aligned}
& Y_{t}=\phi_{0}+\sum_{j=1}^{n} \alpha_{j} Y_{t-j}+\sum_{j=1}^{n} \beta_{j} X_{t-j}+\varepsilon_{1 t} \\
& X_{t}=\lambda_{0}+\sum_{j=1}^{n} \delta_{j} X_{t-j}+\sum_{j=1}^{n} \omega_{j} Y_{t-j}+\varepsilon_{2 t}
\end{aligned}
$$

If $\beta=\left(\beta_{1}, \ldots, \beta_{N}\right)^{T}$ is not the zero vector $(0, \ldots 0)^{T}$ and $\omega=\left(\omega_{1}, \ldots \omega_{n}\right)^{T}$ is the zero vector $(0, \ldots 0)^{T}$, then $X$ is said to Granger cause $Y$. If $\omega$ is not the zero vector and $\beta$ is the zero vector, then $Y$ Granger causes $X$. If neither $\beta$ nor $\omega$ is the zero vector, then there is dependence in both directions and thus feedback between $X$ and $Y$. If both $\beta$ and $\omega$ are the zero vectors, there is no Granger causality $\quad \phi_{0}$ and $\lambda_{0}$ represent intercepts for each equation. Kodra, Chatterjee and Ganguly (2011).

A caveat is that if $X$ seems to cause $Y$ but is simply correlated with $Z$, which lies outside the model and which actually causes $Y$, then it is possible to wrongly determine $X$ as the causal influence [Kodra et al, 2011]. In this regard, there are of course other major determinants of Earth's climate changes such as precession, obliquity and eccentricity of the Earth's orbit [Imbrie et al, 1993, Berger, 1978] that can be seen emerging in our visual charts that are not part of our formal time series analysis. Indeed, ocean dynamics play a major role in the interplay between atmospheric C02 levels and temperature. These factors are beyond the scope of our study.

Possible sources of misleading test results, in relation to GC are: (1) not frequent enough or too frequent sampling, (2) nonlinear causal relationship, (3) time series nonstationarity and non-linearity [Mariusz, 2015]. We overcome less frequent data through linear interpolation of the existing data points in the Vostok Ice Core database, examining the time series for non-stationarity and applying non-causality tests. 
As an improvement to the Granger Causality test conducted by Kang and Larsson [2014], we innovate by taking into account non-linearities.

Kang and Larsson analyze whether there exists long-term causality between temperature and carbon dioxide concentration. The analysis is based on the Vostok Ice Core data from 400,000 to 6,000 years ago, extended by the EPICA Dome C data which go back to 800,000 years ago. They implement the Granger causality test and strongly reject the null hypothesis that carbon dioxide concentration does not Granger cause temperature as well as the reverse hypothesis that temperature does not Granger cause carbon dioxide concentration.

Our study goes beyond that of Kang and Larsson by applying non-linear causality tests as well as considering the dynamic realized volatilities and realized correlation of $\mathrm{C} 02$ and temperature. Our refined modelling approach by taking into account the timevarying nature of volatilities in $\mathrm{CO} 2$ and temperature is thus a major contribution of our paper to the climate literature.

The data for this paper emanates from the Ice Core database that estimates both atmospheric $\mathrm{CO} 2$ and temperature between 420000 and 6000 years ago. Whilst this database is extremely important in gauging global climate change a key issue relates to non-simultaneity. In order to overcome this problem, we use a linear interpolation method of lining up data points to 100 year intervals, so that both the C02 and temperature data are matched at equidistant intervals. In order to test for the robustness of our results we also interpolate the data for 1000 year intervals and find similar results. This database gives access to paleoclimate series that includes local temperature and precipitation rate, moisture source conditions, wind strength and aerosol fluxes of marine, volcanic, terrestrial, cosmogenic and anthropogenic origin [Petit et al 1999].

Our dataset used in analysis is extended by merging data from EPICA Dome $\mathrm{C}$ data which goes back to 800,000 years ago.

Jokimäki [2010, updated 2016] reports a growing body of literature that examines the relationship between the correlation between $\mathrm{CO} 2$ and temperature, none of which looks at the influence of dust, but reach a consensus that $\mathrm{CO} 2$ concentrations lead temperature increases. The papers reported cover a more recent time span, ignore the influence of dust and use Granger Causality based statistical modeling, whereas we implement non-linear causality tests using the latest statistical time series technology emerging as Generalized Correlation. 
Mineral dust aerosols in the atmosphere influence climate directly by absorbing and scattering incoming solar and outgoing infrared radiation [Tegen et al., 1996; Sokolik et al., 2001]. However, scientists have not been actively including dust in their climate models but should model even larger fragments [Cassella, 2018].

It is only a recent phenomenon that scientists have started to explore the role that dust plays in the planet's climate from a more quantitative perspective, but Darwin [1846] documented the presence of dust aerosol in the atmosphere nearly two centuries ago. Dr Karen Kohfeld from Simon Fraser University is well recognized and a strong advocate of the impact that dust has on the climate and established a database DIRTMAP Dust Indicators and Records of Terrestrial and Paleo-environments to collect data to investigate global dust cycles [NSERC, 2010]. From this database it has been demonstrated that increases in winds and decreases in vegetation cover were important contributors to dustiness of the last ice age. Kohfeld stresses the importance that the dust cycle plays in the carbon cycle.

Harrison, Kohfeld et al [2001] examine the complex interaction between natural mineral aerosol (dust) exchanges between the atmosphere, land surface and ocean and discover through simulations that man-made induced climate changes substantially reduce the extent and productivity of natural dust sources in reducing temperature and $\mathrm{CO} 2$.

Maher et al [2010] find that palaeo dust records in sediments and ice cores demonstrate that wind borne mineral aerosol (dust) is strongly connected to climate state. Evan et al. [2014] cast doubt on the ability of current dust models to simulate current regional climate changes.

"As droughts intensify and development expands, the amount of dust blowing around the earth is increasing, affecting everything from mountain snowmelt to the spread of disease. Scientists are just beginning to understand the complex dynamics of dust in a warming world"

[Robbins, 2017].

The inter-play between dust and the global ecology is a new area for scientific exploration. Economic development has brought about a greater increase in deforestation, drought and emergence of deserts which has led to a great increase in dust circulating the globe. Dust in the atmosphere affects the radiative equilibrium of the atmosphere by reflecting or absorbing inward bound solar radiation. However, composition and transportation models of dust in the atmosphere are crude and thus 
regionalized [Tegen, 2003]. Lambert et al (2008) find there is a significant correlation between dust flux and temperature records during glacial periods that is not present during interglacial periods. In particular, Lambert et al (2008) propose that the observed approximately twenty-five fold increase in glacial dust flux over all eight glacial periods can be attributed to a strengthening of South American dust sources. This effect is strengthened by a longer lifetime for atmospheric dust particles in the upper troposphere due to a reduced hydrological cycle during the ice ages. The differing production, transportation and deposition rates of dust and its effect upon climatic changes, across glacial-interglacial periods is supported by Martínez-Garcia et al (2011), over a 4 million years' time period.

Despite the bad publicity surrounding desert storm, dust generated by them eventually brings much needed micronutrients like iron, silicon, calcium, and aluminum to the oceans via the atmosphere [Argonne National Laboratory, 2019]. It is argued that dust in the atmosphere which is soot is short lived [Cowan 2008], i.e. lasts a few days and may have a warming effect upon the atmosphere by absorbing, rather than reflecting sunlight. Perhaps from a climate standpoint, we should distinguish between 'good' and 'bad' dust.

The world's oceans also play a crucial role in the balance of C02 in the atmosphere, with many environmentalists and scientist claiming that this has led to an increased bleaching of the Great Barrier Reef off Australia through greater acidification of the seas. Ocean data is not analyzed in our study, however we recognize that the scientific evidence points towards the ocean temperature and the absorption rates of $\mathrm{CO} 2$ being related [Parliament of Australia, 2009]. In particular, the higher the temperature of the ocean the less $\mathrm{CO} 2$ it is able to hold, which raises the CO2 in the atmosphere and hence temperature, which is a vicious uptrend. The complex global dynamics of this relationship and its impact upon climate are the subject of much ongoing research. However, in our analysis we explore the relationship between glacial and interglacial time periods which per se gives a categorical classification of 'cooler oceans' and 'warmer ocean periods to see the impact upon the dynamic relationship between atmospheric $\mathrm{CO} 2$ and temperature.

Barnett and Seth (2014) develop a multivariate Granger Causality tool kit for investigating time series.

\section{DATA DESCRPTION: DESCRIPTIVE STATISTICS AND GRAPHS}

In our study we use three datasets - $\mathrm{CO} 2$, temperature and dust. All three are retrieved from National Centers for Environmental Information (https://www.ncdc.noaa.gov/). The datasets have records at different ages. We identify a common period for all three datasets, which begins 798500 years ago and end 200 years ago. 
In order to solve the problem of mismatching data points across the datasets, we apply linear interpolation with 100 year interval to each dataset. Graph 1. visualizes the time series following the interpolation.

\section{Graph 1. Linear Interpolation - 100Y}
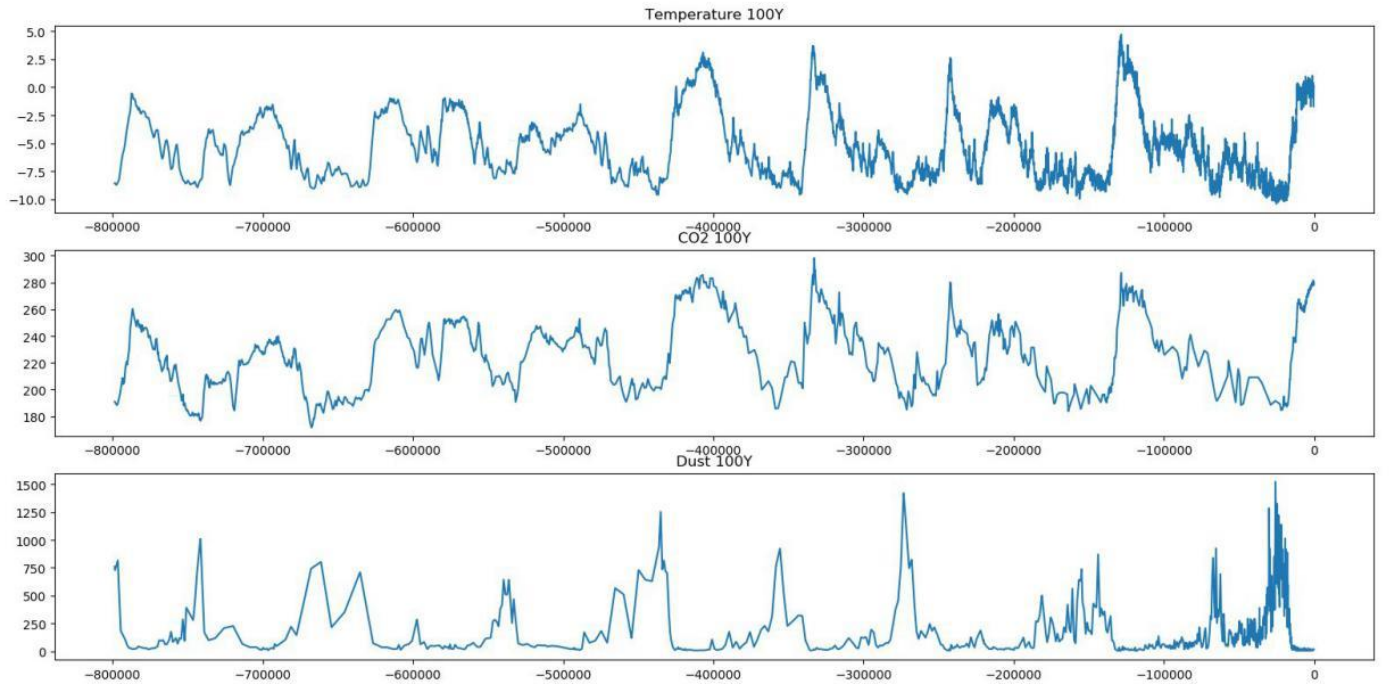

Already from Graph 1., we can visually detect periods where temperature and $\mathrm{CO} 2$ move in the same direction, whereas dust levels move at the opposite direction at the same periods.

We test the robustness of the results by also interpolating the source data with 1000 year interval. On Graph 2., we can observe the time series in 1000 year interval and conclude that they do indeed appear similar. Furthermore, in Table 1. is given the descriptive statistics for all three datasets based on source data, 100 year and 1000 year interval interpolation. The statistics for the two different interpolation are quite close for each respective dataset. 


\section{Graph 2. Linear Interpolation - 1000Y}
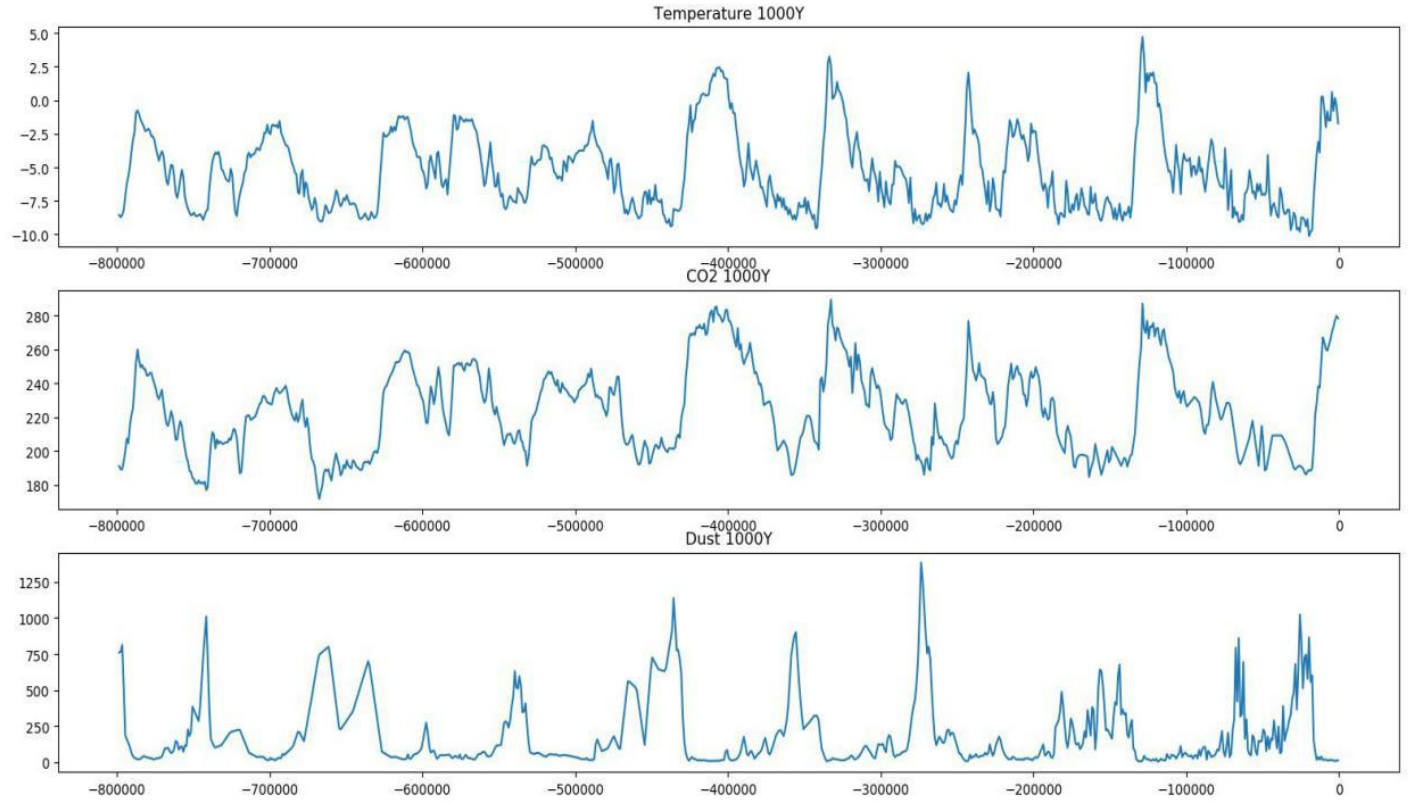

Table 1. Descriptive Statistics

\begin{tabular}{|c|c|c|c|c|c|c|c|c|c|}
\hline \multirow[b]{2}{*}{ Statistic } & \multicolumn{3}{|c|}{ Temperature } & \multicolumn{3}{|c|}{$\mathrm{CO} 2$} & \multicolumn{3}{|c|}{ Dust } \\
\hline & $\begin{array}{c}\text { Source } \\
\text { Data }\end{array}$ & $\mid \begin{array}{c}\mid \text { Interpolation } \\
100\end{array}$ & $\begin{array}{c}\text { terpolation } \\
1000\end{array}$ & $\begin{array}{c}\text { Source } \\
\text { Data }\end{array}$ & $\mid \begin{array}{c}\mid \text { Interpolation } \\
100\end{array}$ & $\begin{array}{c}\text { nterpolation } \\
1000\end{array}$ & $\begin{array}{c}\text { Source } \\
\text { Data }\end{array}$ & $\mid \begin{array}{c}\mid \text { Interpolation } \\
100\end{array}$ & \begin{tabular}{|} 
Interpolatio \\
n 1000
\end{tabular} \\
\hline Observations & 5785 & 7983 & 799 & 1095 & 7983 & 799 & 1154 & 7983 & 799 \\
\hline Mean & -4.58022 & -5.30057 & -5.30318 & 230.79607 & 223.80119 & 223.77966 & \begin{tabular}{|c|}
160.01358 \\
\end{tabular} & 191.95632 & 192.64896 \\
\hline Median & -5.2 & -5.77609 & -5.81173 & 231.4 & 222.23448 & 222.24452 & 51.5625 & 90.47195 & 91.02721 \\
\hline Minimum & -10.58 & -10.40889 & -10.11875 & 171.6 & 171.73222 & 171.73223 & 2.695 & 2.99991 & 3.84305 \\
\hline Maximum & 5.46 & 4.71 & 4.71 & 298.6 & 298.17592 & 289.24814 & 1525 & \begin{tabular}{|l|l|}
1523.25000 \\
\end{tabular} & 1383.62771 \\
\hline Std & 3.44697 & 2.89982 & 2.89941 & 27.55501 & 25.41082 & 25.42266 & \begin{tabular}{|l|}
241.99248 \\
\end{tabular} & 231.96672 & 231.12413 \\
\hline CV & -0.75251 & -0.54708 & -0.54639 & 0.11934 & 0.11353 & 0.11353 & 1.51167 & 1.20836 & 1.19897 \\
\hline Skewness & 0.48457 & 0.72965 & 0.74222 & 0.02766 & 0.36781 & 0.36544 & 2.47815 & 1.86602 & 1.79878 \\
\hline Kurtosis & -0.77432 & -0.11004 & -0.08085 & -0.94476 & -0.94476 & -0.68907 & 6.90709 & 3.36745 & 2.94698 \\
\hline $5 \%$ quantile & -9.14 & -8.90586 & -8.84613 & 188 & 188.76920 & 188.91059 & 7.711 & 13.96239 & 13.88243 \\
\hline $95 \%$ quantile & 0.47600 & 0.38645 & 0.33549 & 275.88 & 271.88204 & 272.19485 & 714.04999 & 723.38278 & 723.58265 \\
\hline $\begin{array}{l}\text { Interquartile } \\
\text { Range }\end{array}$ & 5.63 & 4.20570 & 4.28393 & 43.94999 & 38.72510 & 38.88301 & 174.469978 & \begin{tabular}{l|l|}
3 & 215.62111
\end{tabular} & 218.95883 \\
\hline
\end{tabular}


In the next three graphs (3., 4. and 5.), we again provide visualization of the three time series with $1000 \mathrm{Y}$ interpolation, however included are the rolling mean and standard deviation, where the rolling period is 100. Although the data is quite volatile, the rolling mean and standard deviation remain stable in most periods, with possible evidence of mean reversion.

\section{Graph 3. Rolling Statistics - Temperature}

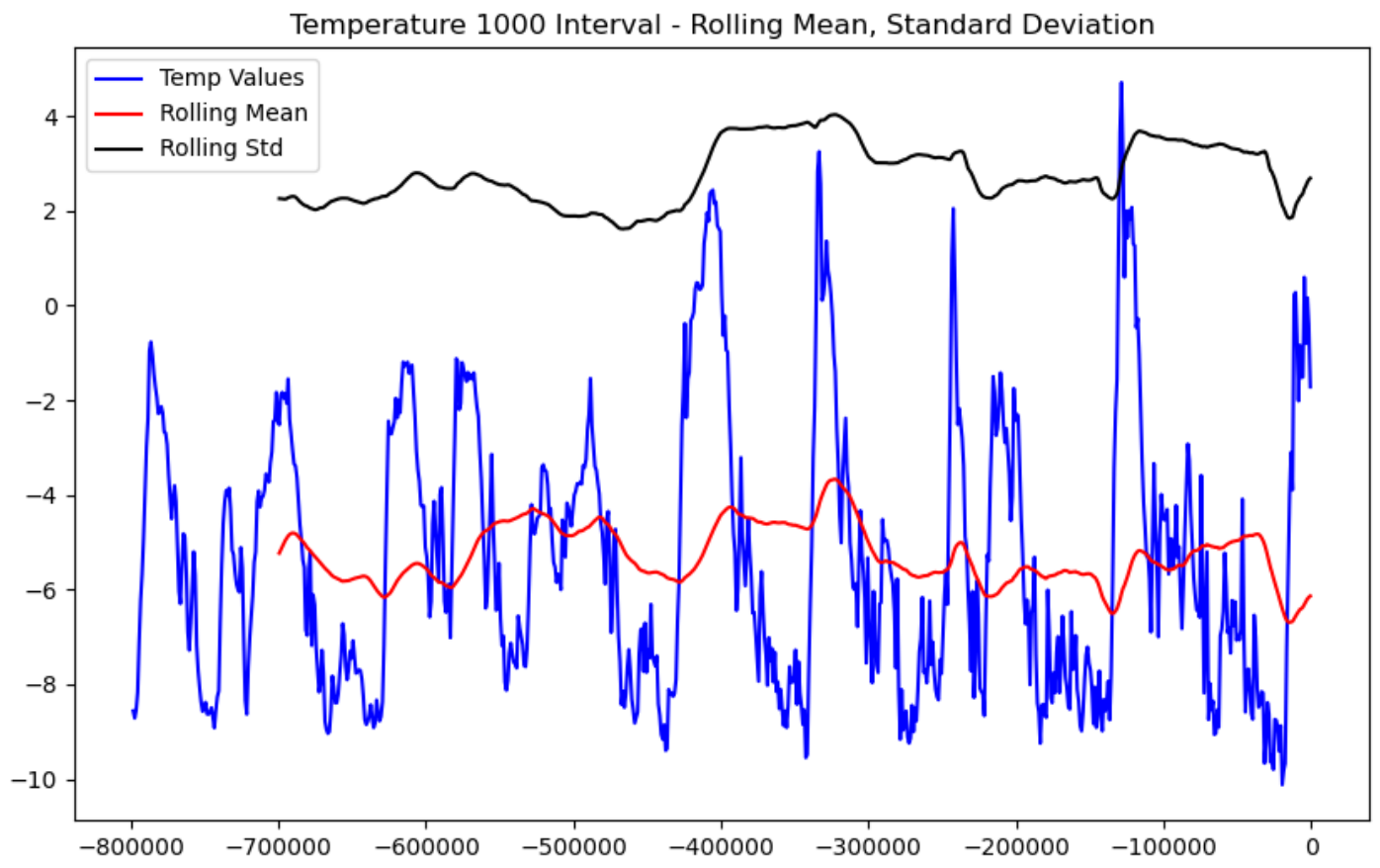


Graph 4. Rolling Statistics - CO2

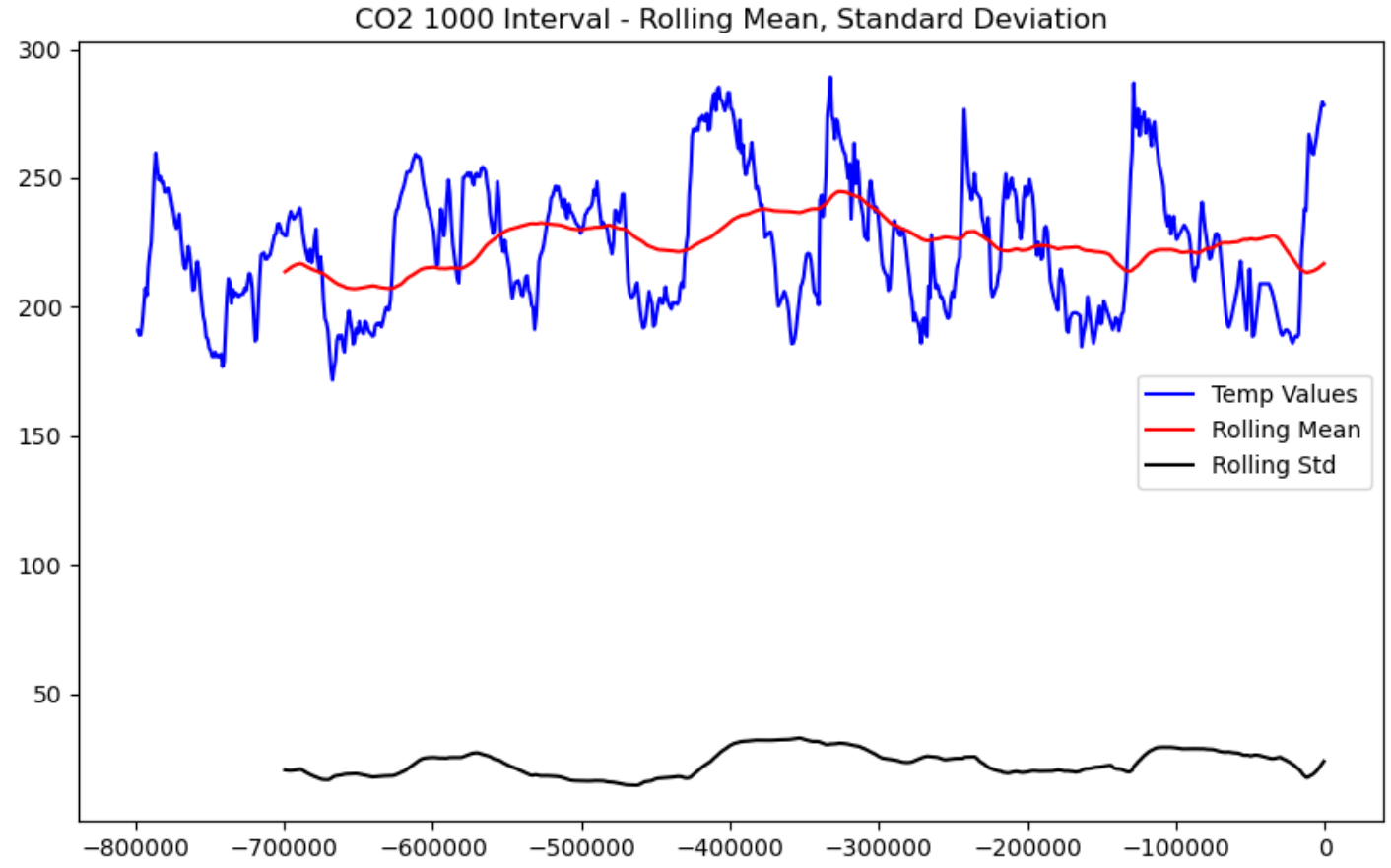

\section{Graph 5. Rolling Statistics - Dust}

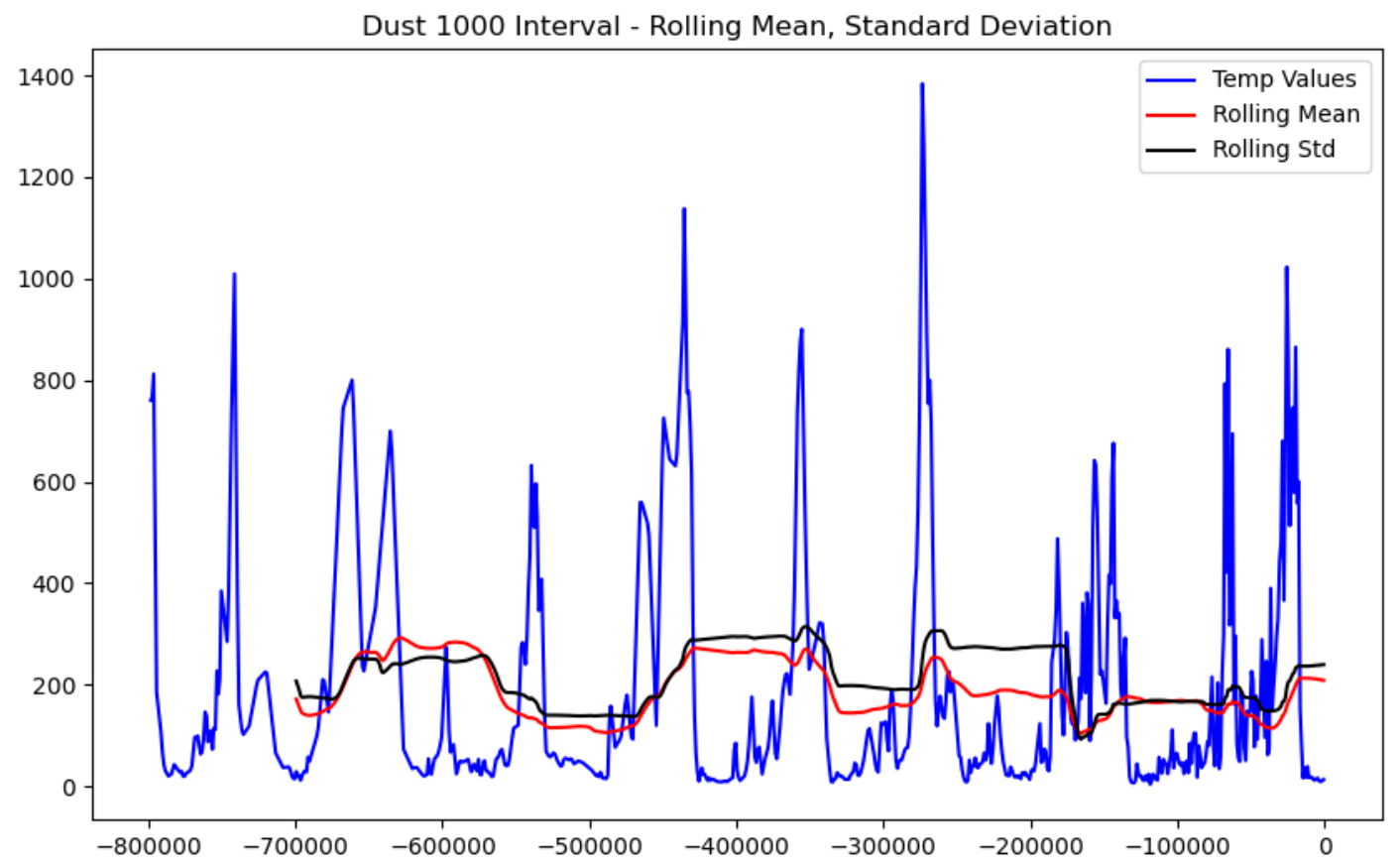


Finally, we also explore the correlation between each pair of variables. On graphs 6., 7. and 8., we see the rolling correlation between temperature and CO2, temperature and dust, and CO2 and Dust. We use a 100 year window and on each graph the top shows the 100 years interpolation and the bottom the 1000 years interpolation. The 100 years interpolated data displays strong volatility in the correlation, but 1000 years interpolated data seems to imply that temperature and $\mathrm{CO} 2$ are positively correlated usually with $0.85-0.90$ correlation, whereas dust is negatively correlated with both temperature and $\mathrm{CO} 2$ with the correlation fluctuating between -0.6 and -0.8 .

Graph 6. Rolling Correlation - Temperature and CO2
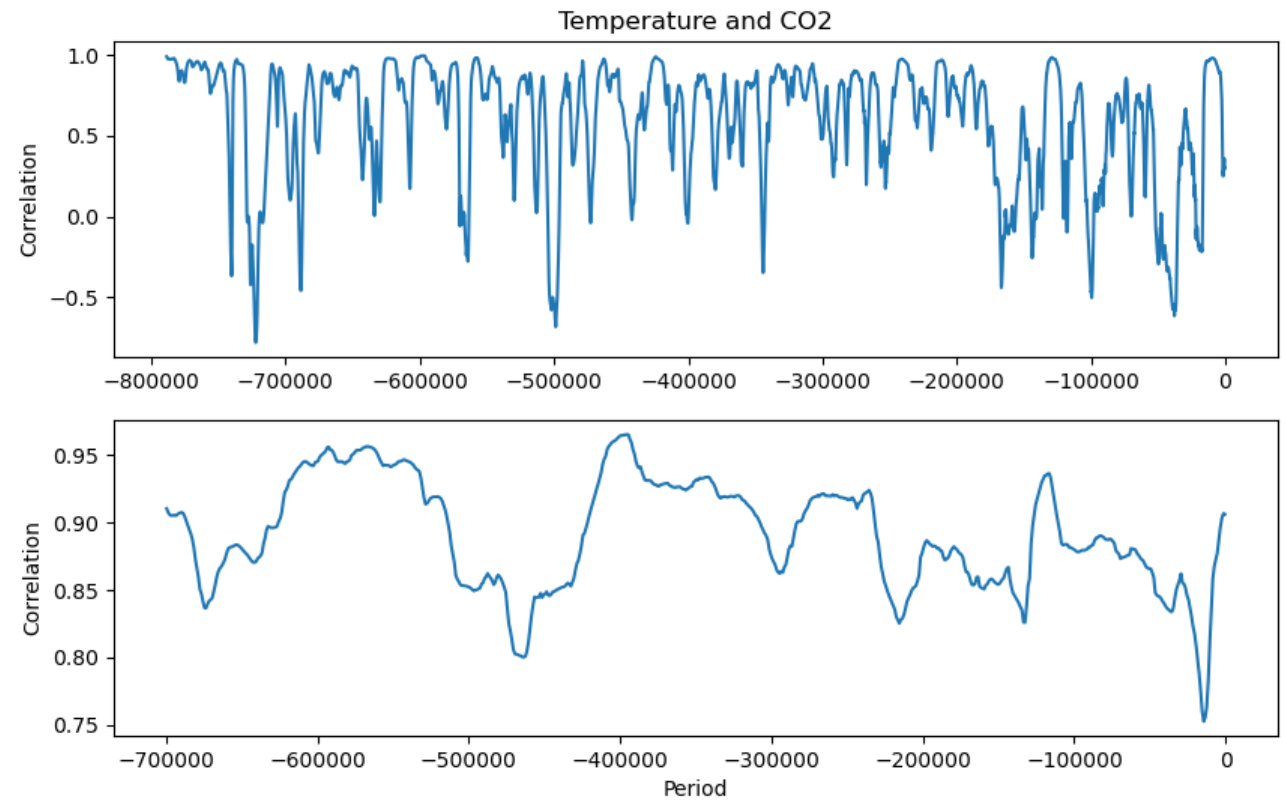


\section{Graph 7. Rolling Correlation - Temperature and Dust}
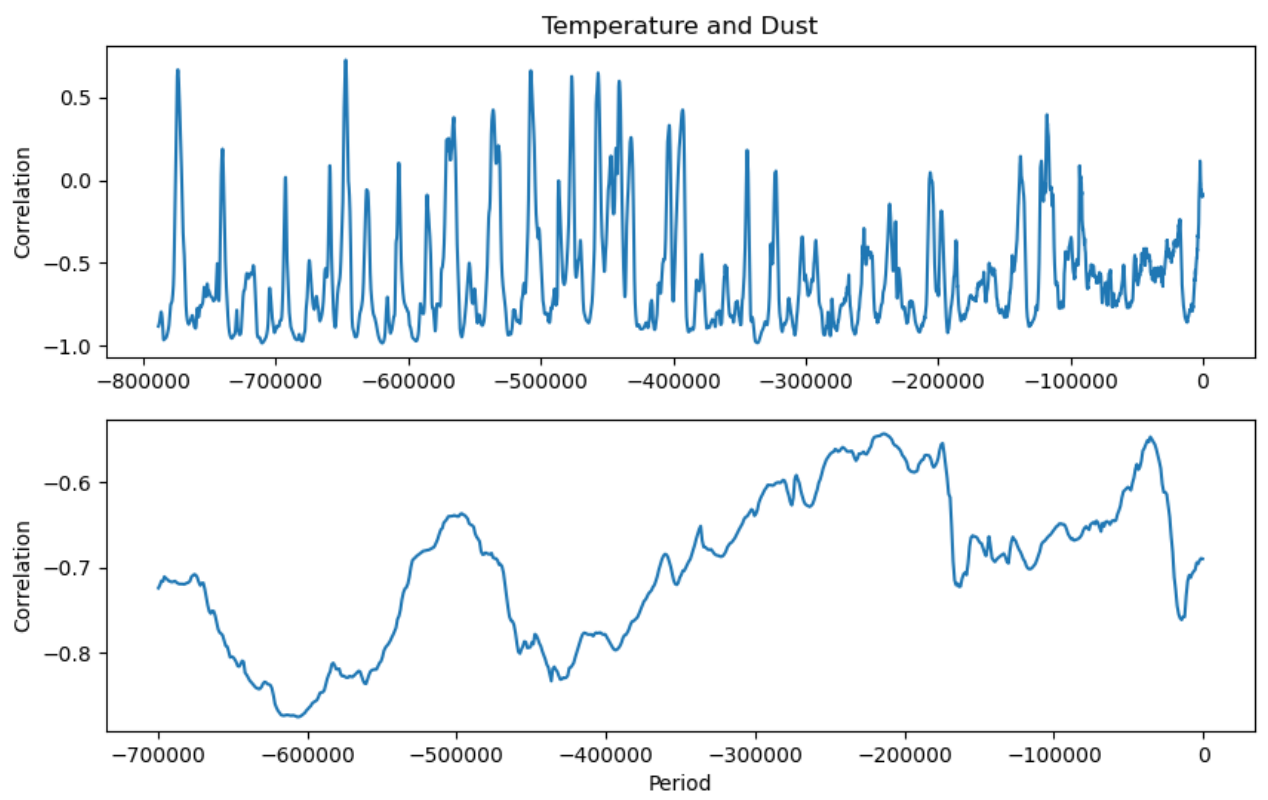

\section{Graph 8. Rolling Correlation - CO2 and Dust}
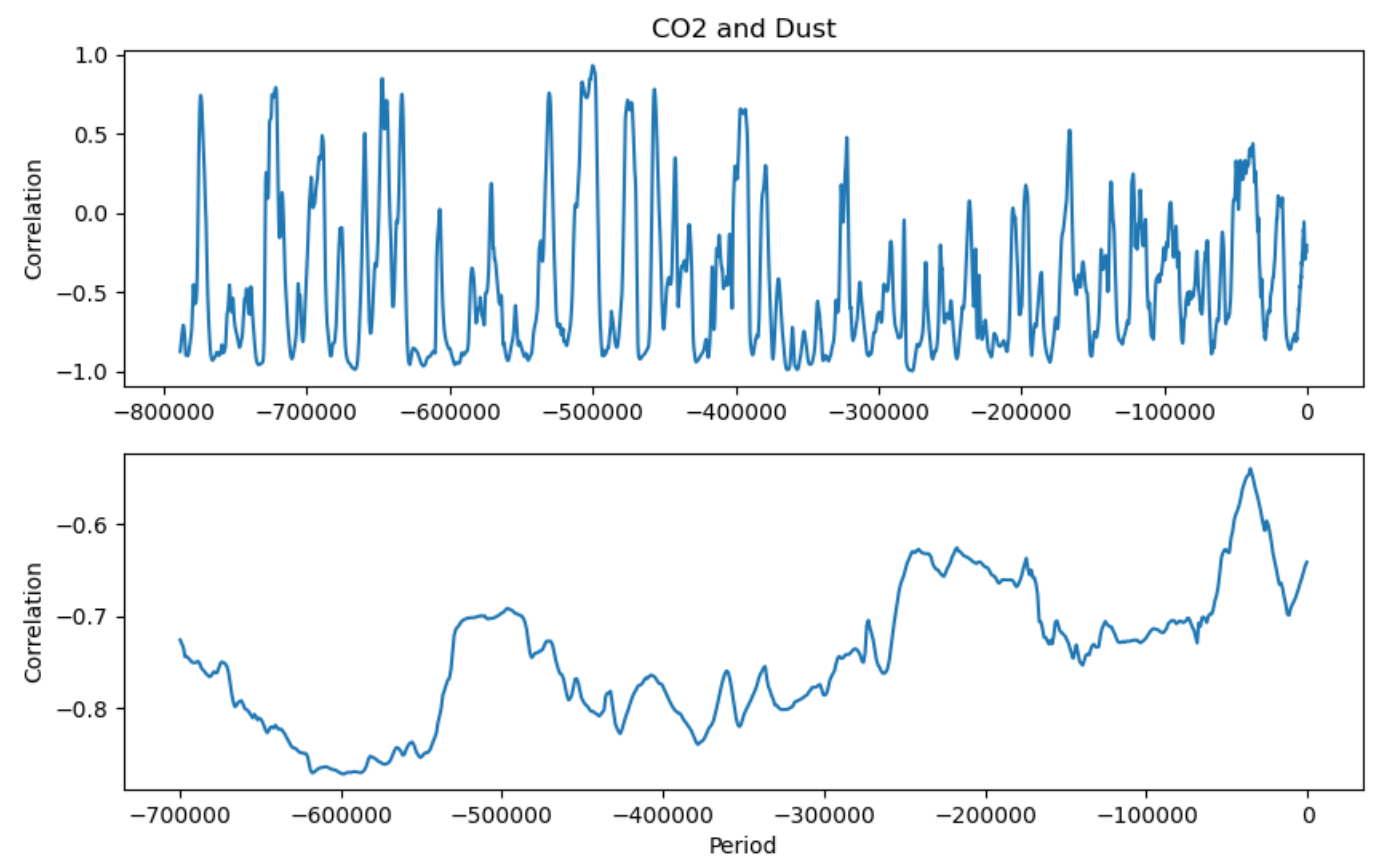


\section{ADVANCED TIME SERIES MODELLING}

Zheng, Shi, and Zhang (2012) suggested that Pearson's correlation, when used as a measure of explained variance, is well understood, but a major limitation is that it does not account for asymmetry. Zheng, Shi, and Zhang (2012) suggested a broadly applicable correlation measure, and considered a pair of generalized measures of correlation (GMC) that deal with asymmetry in the explained variance, and linear or nonlinear relations between random variables.

Vinod (2017) developed the R library package "generalCorr". Allen and Hooper (2018) used the metric to analyze causal relations between the VIX, S\&P500, and the realized volatility (RV) of the S\&P500 sampled at 5-min intervals. Allen and McAleer (2020) explored the statistical antecedents of the metric.

Zheng et al. (2012) draw attention to the computation of the coefficient of determination, $R^{2}$ in a linear regression model, in which the total variation in the response variable is partitioned into two component sums of squares, that is, explained variation due to regression and unexplained variation. Zheng et al. (2012) introduce their GMC based on a well-known variance decomposition formula:

$$
\operatorname{var}(x)=\operatorname{var}(E(X \mid Y))+E(\operatorname{var}(X \mid Y))
$$

whenever $E\left(Y^{2}\right)<\infty$ and $E\left(X^{2}\right)<\infty$. Note that $\operatorname{var}(E(X \mid Y))$ is the variance of conditional mean of $X$ given $Y$, and hence $\operatorname{var}(E(X \mid Y)) / \operatorname{var}(X)$ can certainly be interpreted as the explained variance of $X$ by $Y$. We have

$$
\frac{\operatorname{var}(E(X \mid Y))}{\operatorname{var}(X)}=1-\frac{E(\operatorname{var}(X \mid Y))}{\operatorname{var}(X)}=1-\frac{E\left[\{X-E(X \mid Y)\}^{2}\right]}{\operatorname{var}(X)}
$$

Similarly, they define the explained variance of $Y$ given $X$. They suggest that it is natural to introduce a pair of GMC as: 


$$
G M C(X \mid Y), G M C(Y \mid X)=\left\{1-\frac{E[Y-E(Y \mid X)]^{2}}{\operatorname{var}(Y)}, 1-\frac{E\left[(X-E(X \mid Y)]^{2}\right.}{\operatorname{var}(X)}\right\}
$$

It is worth noting that in a regression model $Y=g(X)+\varepsilon$, the $R^{2}$ is identical to $\operatorname{GMC}(Y \mid X)$ when $g(X)$ is chosen to be $E(Y X)$. Other than this identity, the $R^{2}$ has not been used in studying asymmetric explained variances between random variables. Because the main usage of $R^{2}$ is in regression analysis, GMC seems a natural choice of measures of explained variances between random variables. The GMC can depict the nonlinear or asymmetric relation between two variables. They are true measures for explained variances. A review of measures of antecedents of the GMC metric is provided by Allen and McAleer (2020).

A pair of GMC measures the association between two random variables globally, and it deals with asymmetry, nonlinearity, and beyond. In our context, $\operatorname{GMC}(Y X)>\operatorname{GMC}(X \mid Y$ ), $\operatorname{GMC}(Y \mid X)<\operatorname{GMC}(X \mid Y)$, and $\operatorname{GMC}(Y X)=\operatorname{GMC}(X \mid Y)$ lead to more meaningful statistical inference. When $\operatorname{GMC}(Y X)>\operatorname{GMC}(X \mid Y), X$ is more important than $Y$.

We undertook a GMC analysis on pairs of variables, starting with Temp and CO2. This analysis was done with contemporaneous 1000 year spaced data. It can be seen below that the GMC correlation of Temp with $\mathrm{CO} 2$ is not quite as high as that with $\mathrm{CO} 2$ and temp, then respective values being 0.8959721 and 0.8968893 .

This suggests that $\mathrm{CO} 2$ better explains Temp than Temp does CO2. The third value below is the Pearson correlation coefficient. The fourth value is the probability which shows the relationship is highly significant.

GMC Analysis of Temp and $\mathrm{CO} 2$ using data intervalled at 1000 years.

\begin{tabular}{|l|l|l|}
\hline & TEMP & CO2 \\
\hline GMC & 0.8959721 & 0.8968893 \\
\hline Pearson Correlation & 0.8857599 & \\
\hline Probability & $6.694055 \mathrm{e}-268$ & \\
\hline
\end{tabular}

We then ran a similar analysis of the relationship between Temp and Dust, and the results, shown below, suggest that Temp better explains Dust than vice-versa. It makes intuitive sense that there is a negative relationship between these two variables. 


\begin{tabular}{|l|l|l|}
\hline & TEMP & Dust \\
\hline GMC & -0.8986029 & -0.8119205 \\
\hline Pearson Correlation & -0.6610334 & \\
\hline Probability & $1.653772 \mathrm{e}-101$ & \\
\hline
\end{tabular}

Finally, we ran an analysis between $\mathrm{CO} 2$ and Dust and it looks like C02 better explains

Dust than vice versa. Once again the relationship is negative.

\begin{tabular}{|l|l|l|}
\hline & CO2 & Dust \\
\hline GMC & -0.8715874 & -0.780536 \\
\hline Pearson Correlation & -0.6849441 & \\
\hline Probability & $1.038898 \mathrm{e}-111$ & \\
\hline
\end{tabular}

\section{SUMMARY AND CONCLUSION}

There is a growing interest in the research literature to examine the influence of dust upon climate, but has been largely ignored. In this regard, our study examines a time series of $\mathrm{CO} 2$, temperature and dust spanning 800000 years, with particular emphasis upon the causality between these variables, as well as the dynamic nature of correlations and volatilities. A major innovation in our paper is the use of Generalized Correlation Method which should have wide reaching uses as a tool in climate research and improve methodology.

The analysis shows that all three variables (temperature, dust and $\mathrm{CO} 2$ ) are volatile, however their rolling mean and standard deviation remain stable for most of the periods. It appears that the data of all three time series stay within a limited range, which is likely to be mean reverting. Additionally, the data analysis suggests positive correlation between temperature and $\mathrm{CO} 2$, while dust is negatively correlated with both temperature and $\mathrm{CO} 2$.

The application of the non-parametric Generalized Measure of Correlation (GMC), to our 1000 year data sets, in a pairwise fashion, suggested that CO2 better explains temperature than temperature does $\mathrm{CO} 2$, that temperature better explains dust than dust does temperature, and finally that $\mathrm{CO} 2$ better explains dust than vice -versa. The results suggest that the latter two pairs of relationships are negative which makes intuitive sense. Man is not only ambitious to collect more data through remote sensing and satellite sensing in relation to dust, but also in their desire to control future global temperature levels through $\mathrm{CO} 2$ emissions but also to engage in global environmental engineering, perhaps through 'seeding' of the atmosphere with dust and 
aerosols coupled with more effective land management. Our findings thus have very important global climate change policy implications as we find that dust can dramatically alter the relationship between $\mathrm{CO} 2$ and temperature, perhaps to the extent that the relationship between these two variables can enter a virtuous feedback loop by finding ways to reduce the likely acidification of the oceans and harnessing the power of 'good dust', benefiting all ecosystems on this planet.

\section{REFERENCES}

Alfredo Martínez-Garcia, Antoni Rosell-Melé, Samuel L. Jaccard, Walter Geibert, Daniel M. Sigman \& Gerald H. Haug (2011). 'Southern Ocean dust-climate coupling over the past four million years', Nature, 476, Pages 312-315.

Allen, D. E. and M. McAleer (2020) "Generalized Measures of Correlation for Asymmetry, Nonlinearity, and Beyond": Some Antecedents on Causality, The Journal of the American Statistical Association, https://www.tandfonline.com/loi/uasa20

Argonne National Laboratory (2019). Bio-Available Iron from Atmospheric Dust. Environmental Science Division, http://www.evs.anl.gov/research areas/highlights/atmospheric-dust.cfm. [Accessed 26/7/2019].

Barnett, Lionel Anil K.Seth (2014). 'The MVGC multivariate Granger causality toolbox: A new approach to Granger-causal inference', Journal of Neuroscience Methods, Volume 223, 15 February, Pages 50-68.

Cassella, C. (2008). 'Giant Dust Is Spreading Across The World, Defying The Laws Of Physics', Science Alert, April.

Cook, John, Naomi Oreskes, Peter T Doran , William R L Anderegg, Bart Verheggen, Ed W Maibach, J Stuart Carlton, Stephan Lewandowsky, Andrew G Skuce, Sarah A Green, Dana Nuccitelli, Peter Jacobs, Mark Richardson, Bärbel Winkler, Rob Painting and Ken Rice (2016). 'Consensus on consensus: a synthesis of consensus estimates on human-caused global warming', Environmental Research Letters, 11. Pages 1-7.

Cowan, R. (2008). 'Dust plays a huge role in Climate Change', The Christian Monitor, April.

Darwin, C. (1846). 'An account of the fine dust which often falls on the vessels in the Atlantic Ocean', Quarterly Journal of the Geological Society, Volume 2, Pages 26-30.

Evan, A., C. Flamant, S. Fledler and O. Doherty [2014]. 'An analysis of aeolian dust in climate models', Geophysical Research Letters, 41, Pages 5996-6001.

Granger, C. W. J. (1969). 'Investigating Causal Relations By Econometric Models and Cross-Spectral Methods', Econometrica, 37(3): pp. 424-438.

Harrison, S., K Kohfeld, C. Roelandt and T. Claquin [2001]. 'The role of dust in climate changes today, at the last glacial maximum and in the future', Earth Science Reviews, 
Volume 54, Pages 43-80.

J. Imbrie, A. Berger, E. A., Boyle, S. C. Clemens, A. Duffy, W. R. Howard, G. Kukla, J. Kutzbach, D. G. Martinson, A. McIntyre, A. C. Mix, B. Molfino, J. J. Morley, L. C. Peterson, N. G. Pisias, W. L. Prell, M. E. Raymo, N. J. ,Shackleton, J. R. Toggweiler (1993). 'On the structure and origin of major glaciation cycles 2. The 100,000-year cycle', Paleoceanography and Paleoclimatology, Volume8, Issue6, December, Pages 699-735.

Jokimäki, A. (2010, updated 2016), 'Papers on CO2-temperature correlation', AGW Observer.https://agwobserver.wordpress.com/2010/02/18/papers-on-co2-temperaturecorrelation/

Kang, J. and R. Larsson (2014). 'What is the link between temperature and carbon dioxide levels? A Granger causality analysis based on ice core data'. Theoretical and Applied Climatology, May, Volume 116, Issue 3-4, Pages 537-548

Kodra, E., Chatterjee, S. and A. R. Ganguly (2011). 'Exploring Granger Causality Between Global Average Observed Time Series of Carbon Dioxide and Temperature', Theoretical and Applied Climatology, June, Volume 104, Issue 3-4, Pages 325-335.

Lambert F, Delmonte B, Petit JR, Bigler M, Kaufmann PR, Hutterli MA, Stocker TF, Ruth U, Steffensen JP, Maggi V. (2008). 'Dust-climate couplings over the past 800,000 years from the EPICA Dome C ice core', Nature, April, 452, Pages 616-619.

Maher, B. A, J. M. Prospero, D. Mackie, D. Gaiero, P. P. Hesse and Y. Balkanski (2010). 'Global Connections between aeolian dust, climate and ocean biogeochemistry at the present day and at the last glacial maximum', Earth Science Reviews, 99, Pages 61-97.

Mariusz, M. (2015). 'A review of the Granger-causality fallacy', The Journal of Philosophical Economics: Reflections on Economic and Social Issues. VIII. (2). ISSN 1843-2298.

National Sciences and Engineering Research Council (2010). 'Dust in Earth system can affect oceans, carbon cycle, temperatures and health', Science News, 23/2/2010. https://www.sciencedaily.com/releases/2010/02/100219204413.htm

Parliament of Australia (2009). 'Oceans are heating up and acidifying', https://www.aph.gov.au/About Parliament/Parliamentary Departments/Parliamenta

ry Library/Browse by Topic/ClimateChangeold/theClimate/oceans. [Accessed:

29/7/2019].

Petit, J. R., J. Jouzel, D. Raynaud, N. I. Barkov, J.-M. Barnola, I. Basile, M. Bender, J. Chappellaz, M. Davis, G. Delaygue, M. Delmotte, V. M. Kotlyakov, M. Legrand, V. Y. Lipenkov, C. Lorius, L. PÉpin, C. Ritz, E. Saltzman \& M. Stievenard (1999). 'Climate and atmospheric history of the past 420,000 years from the Vostok ice core, Antarctica', Nature, 399, Pages. 429-436.

Robbins, J. (2017). 'Climate Connection: Unraveling the Surprising Ecology of Dust', Yale Environment 360, https://e360.yale.edu/features/climate-connection-unravelingthe-surprising-ecology-of-dust [Accessed: 26/7/2019]. 
Sokolik, I. N, D. M. Winker, G. Bergametti, D. A. Gillette, G. Carmichael, Y. J. Kaufman, L. Gomes, L. Schuetz, J. E. Penner. [2001]. 'Introduction to special section: Outstanding problems in quantifying the radiative impacts of mineral dust', Journal of Geophysical Research, 106(D16), Pages 18015-18027.

Tegen, I. (2003). 'Modelling the mineral dust aerosol cycle in the climate system', Quaternary Science Reviews, Volume 22, Issues 18-19, September, Pages 1821-1834.

Tegen, I., A. A. Lacis and I. Fung (1996). 'The influence on climate forcing of mineral aerosols from disturbed soils', Nature, 380(6573), Pages 419-422.

Vinod, H.D. (2017). "Generalized Correlations and Kernel Causality Using R Package generalCorr", https://cran.r-project.org/web/packages/generalCorr/vignettes/generalCorrvignette.pdf

Vostok Data Series https://cdiac.ess-dive.lbl.gov/trends/co2/ice core co2.html http://cdiac.ess-dive.lbl.gov/ftp/trends/temp/vostok/vostok.1999.temp.dat

Zheng, S., N-Z Shi and Z. Zhang (2012) the Journal of the American Statistical Association, 107(499), Pages 1239-1251. 


\section{Supplementary Appendix: Further Ordinary Least Squares and Time Series Analysis [with regard to Lead-Lags]}

OLS Regression Results

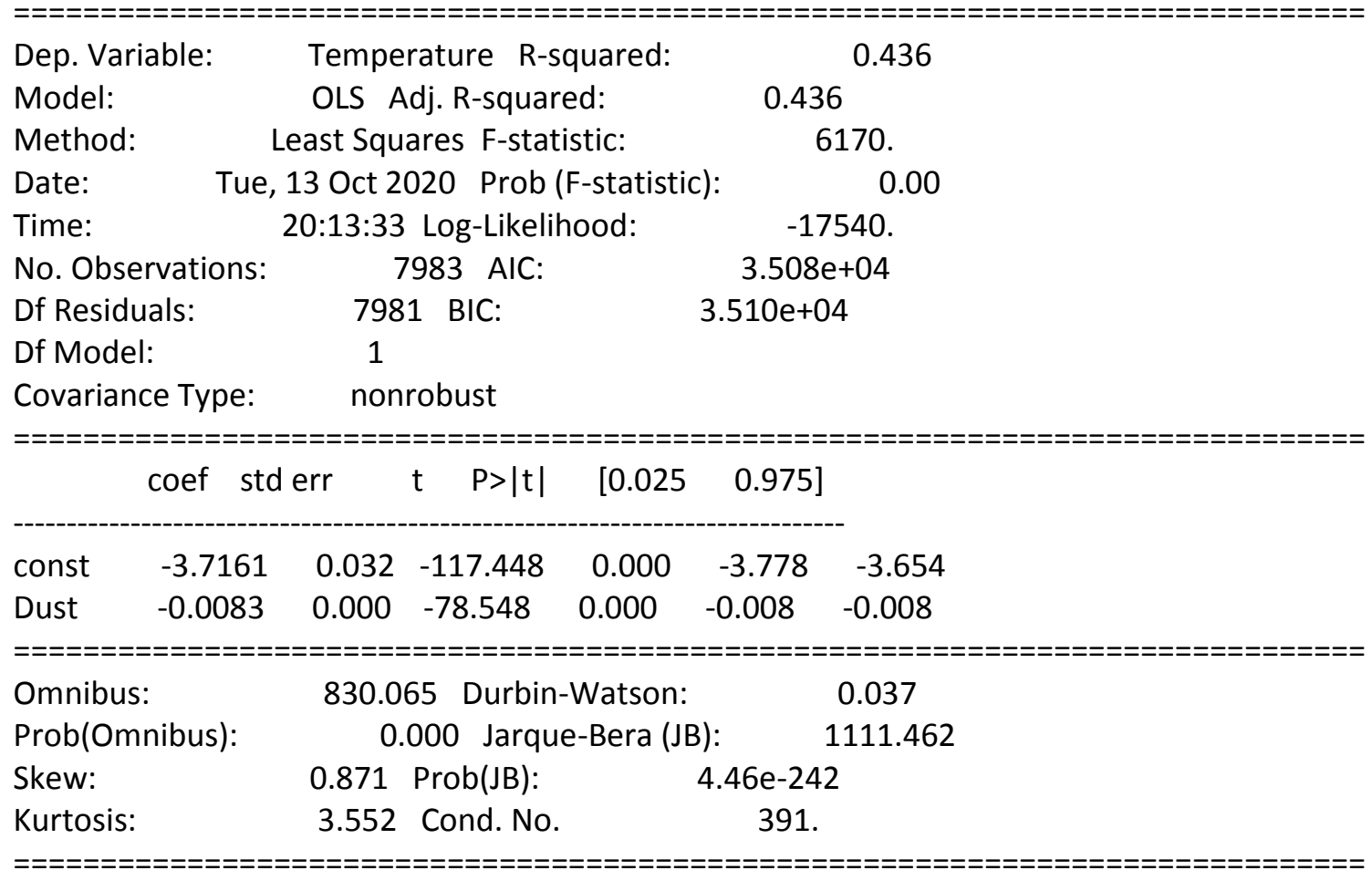

Notes:

[1] Standard Errors assume that the covariance matrix of the errors is correctly specified. "'"!" 


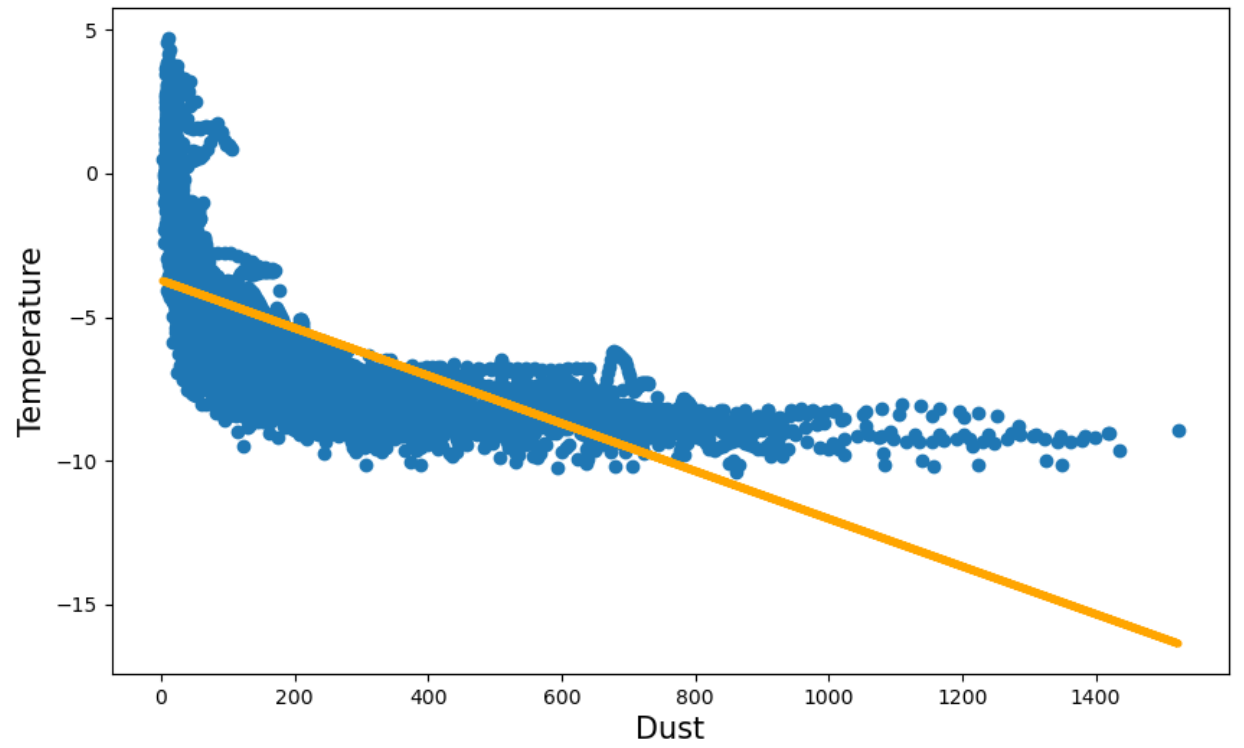

OLS Regression Results

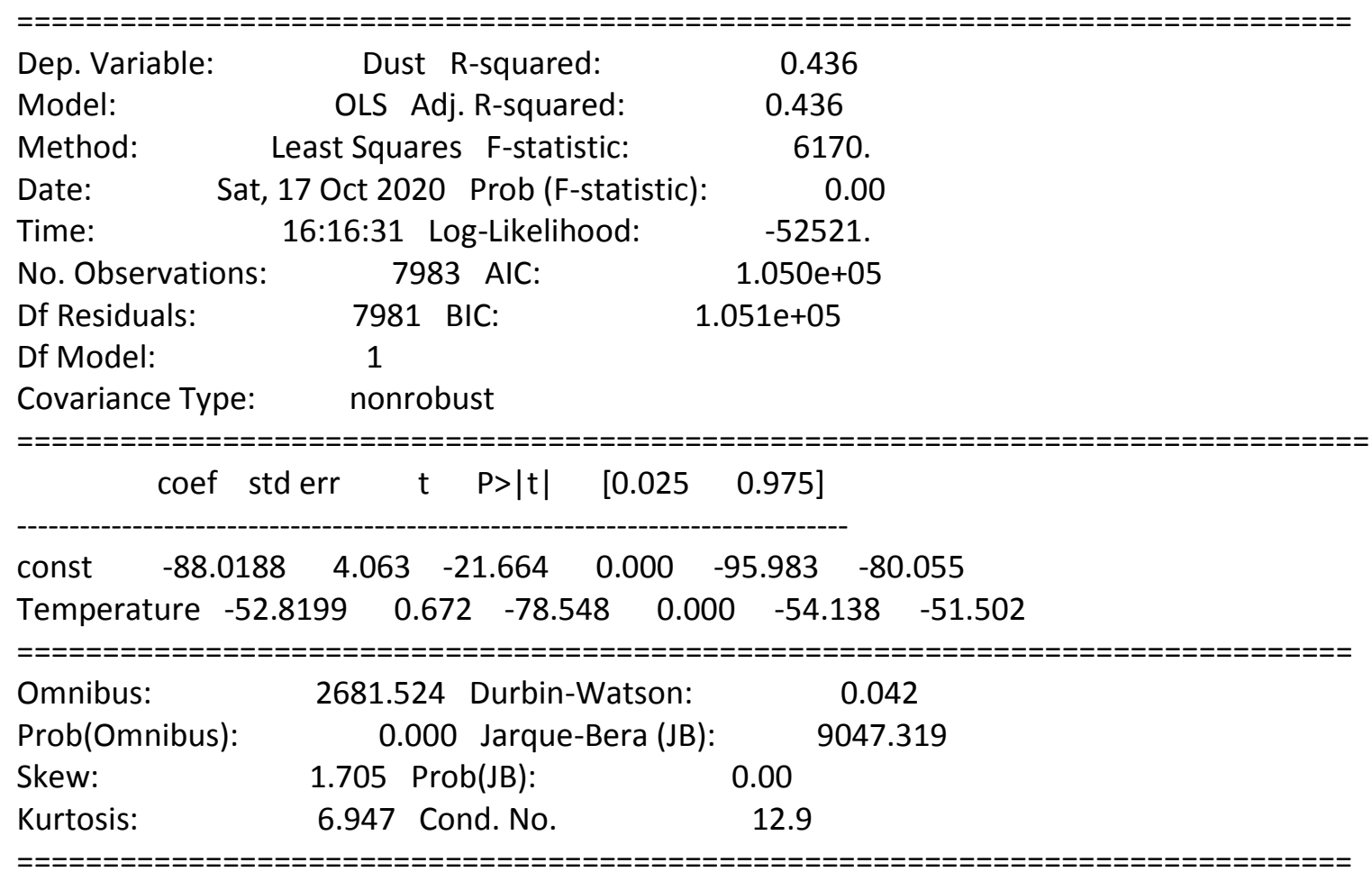


Notes:

[1] Standard Errors assume that the covariance matrix of the errors is correctly specified.

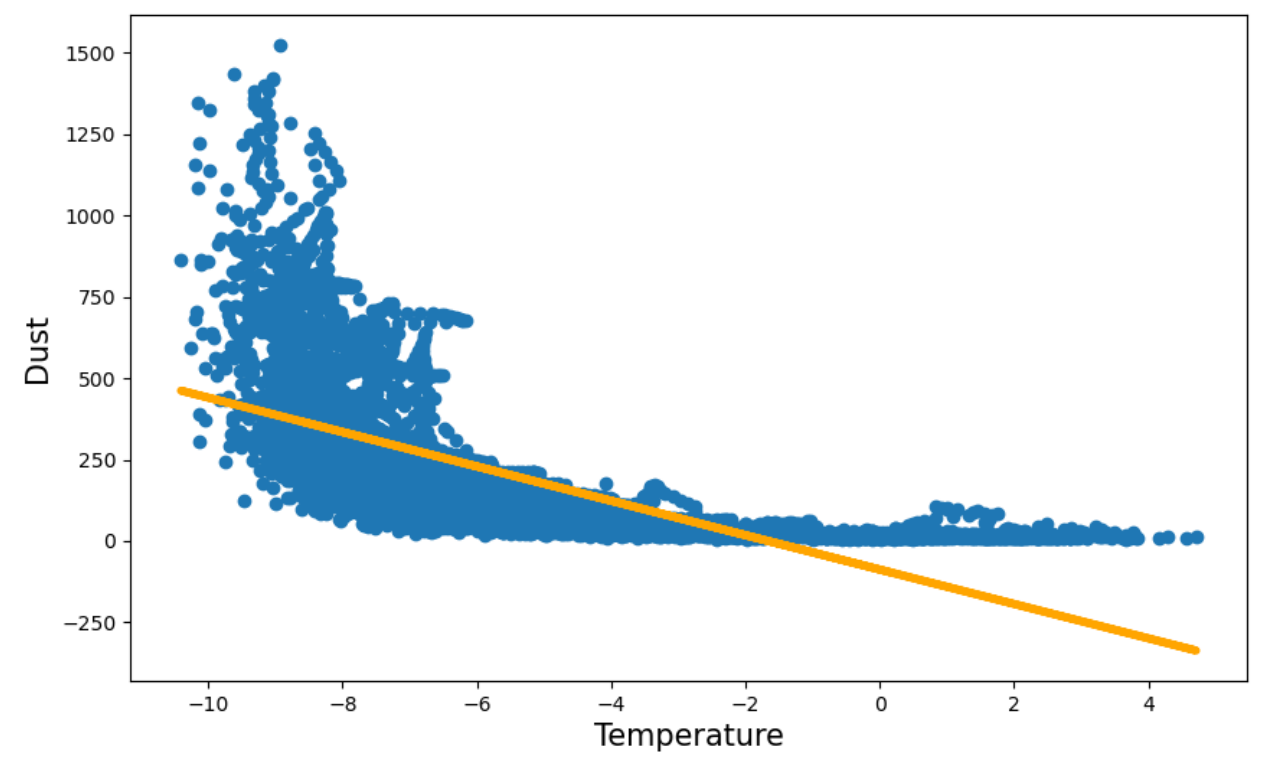

Polynomial Fit $3^{\text {rd }}$ degree - Temp to Dust

$R 2=0.6947$ 


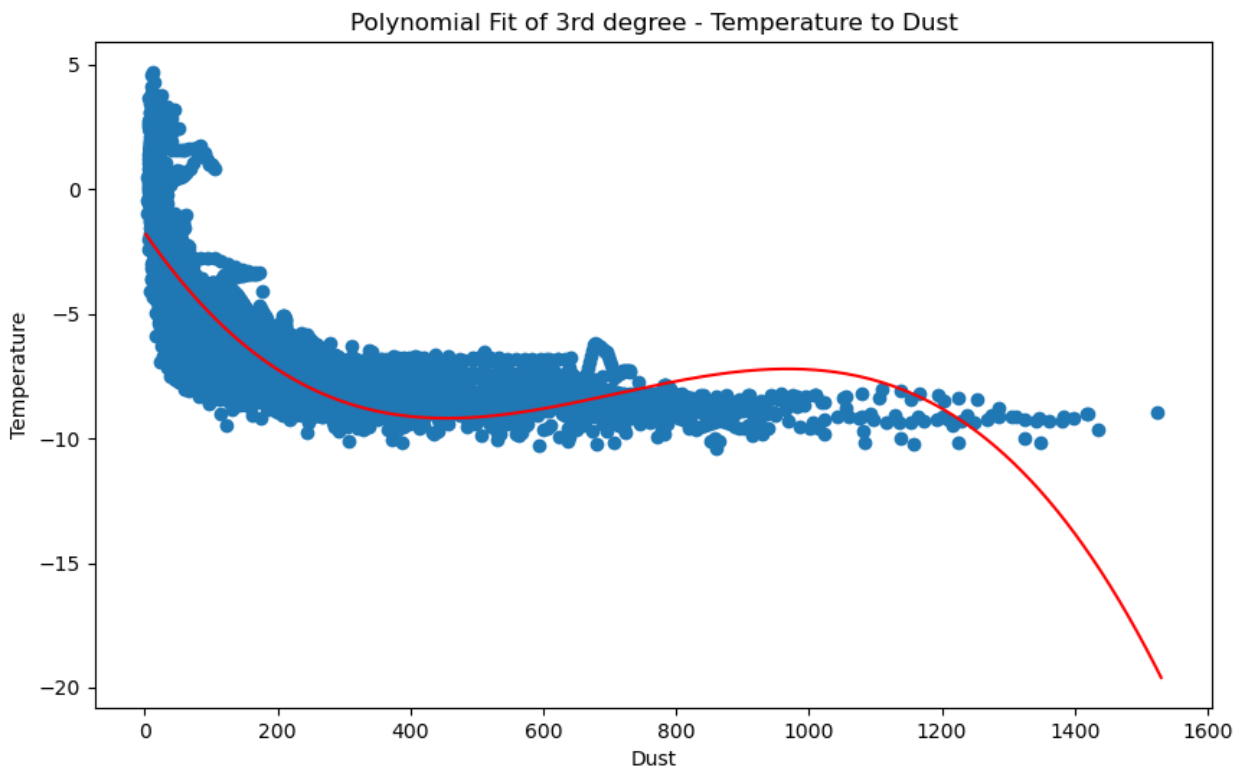

\section{$A C F$ and PACF}

Temperature 100Y
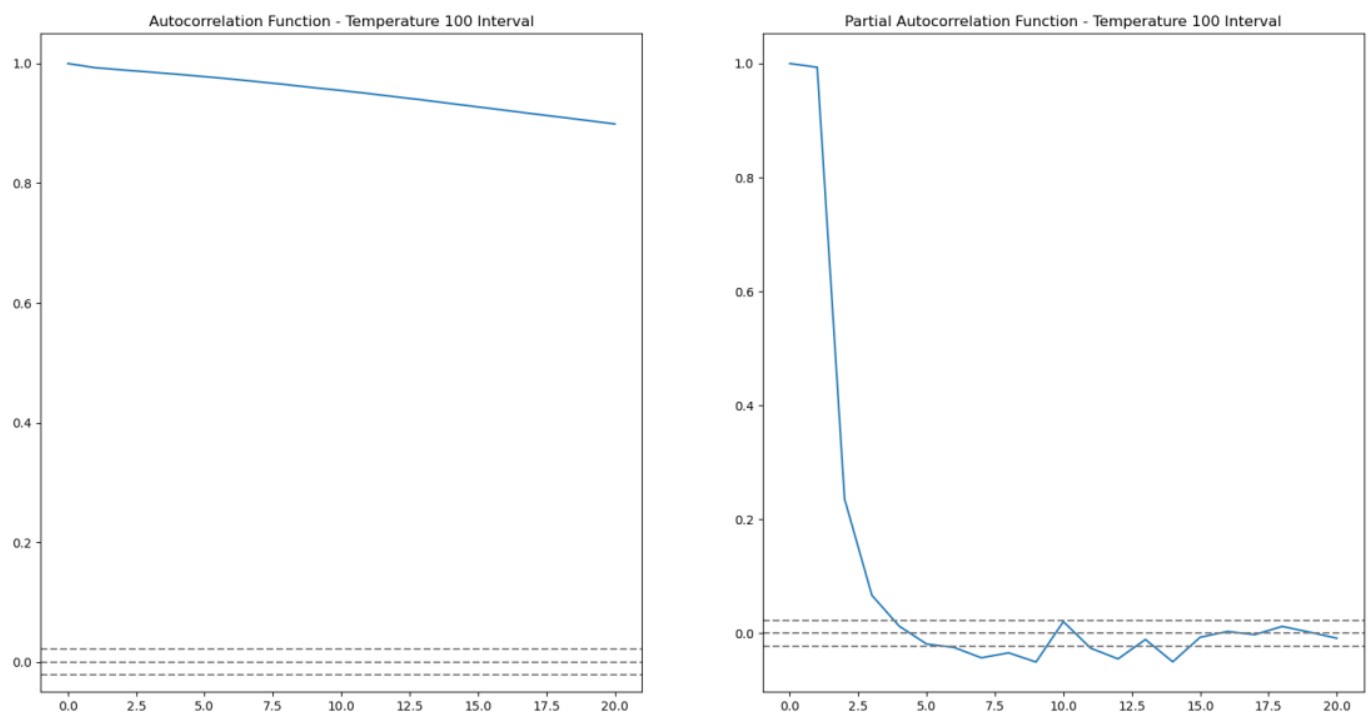
Temperature 1000Y
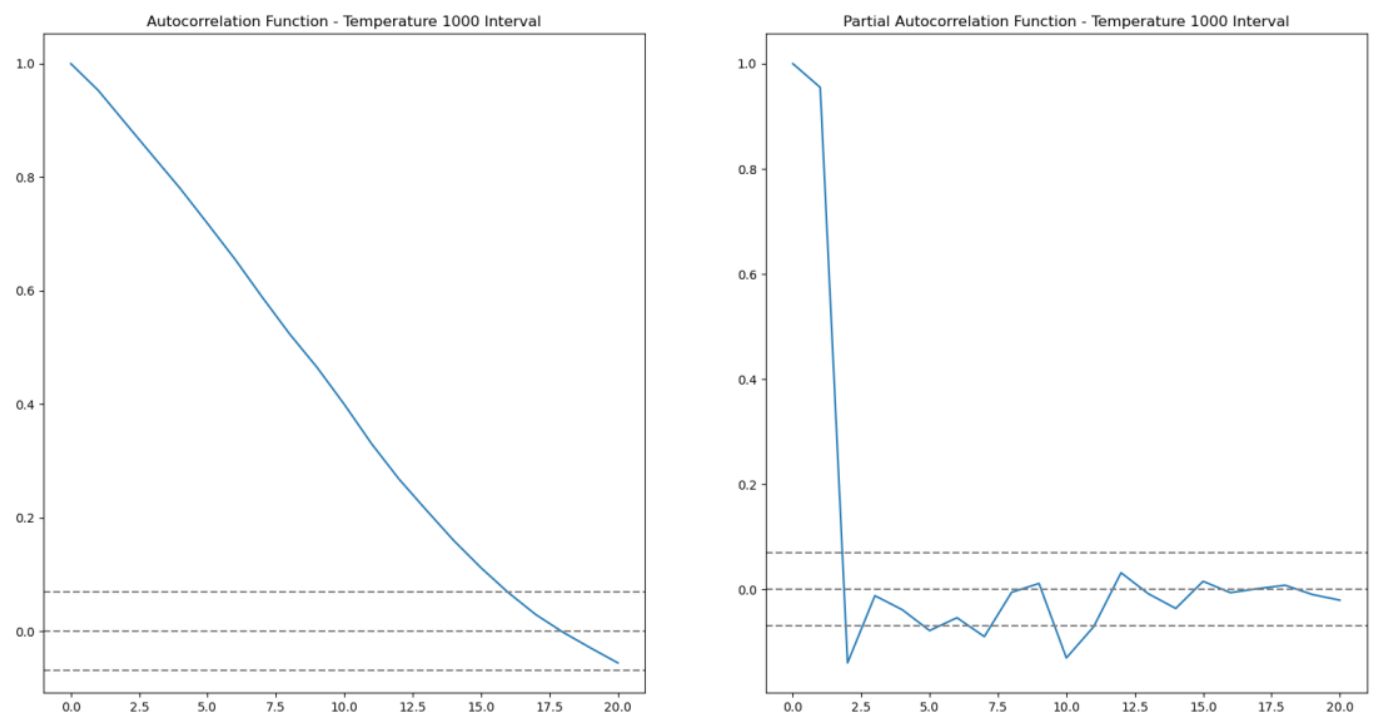
CO2 100Y
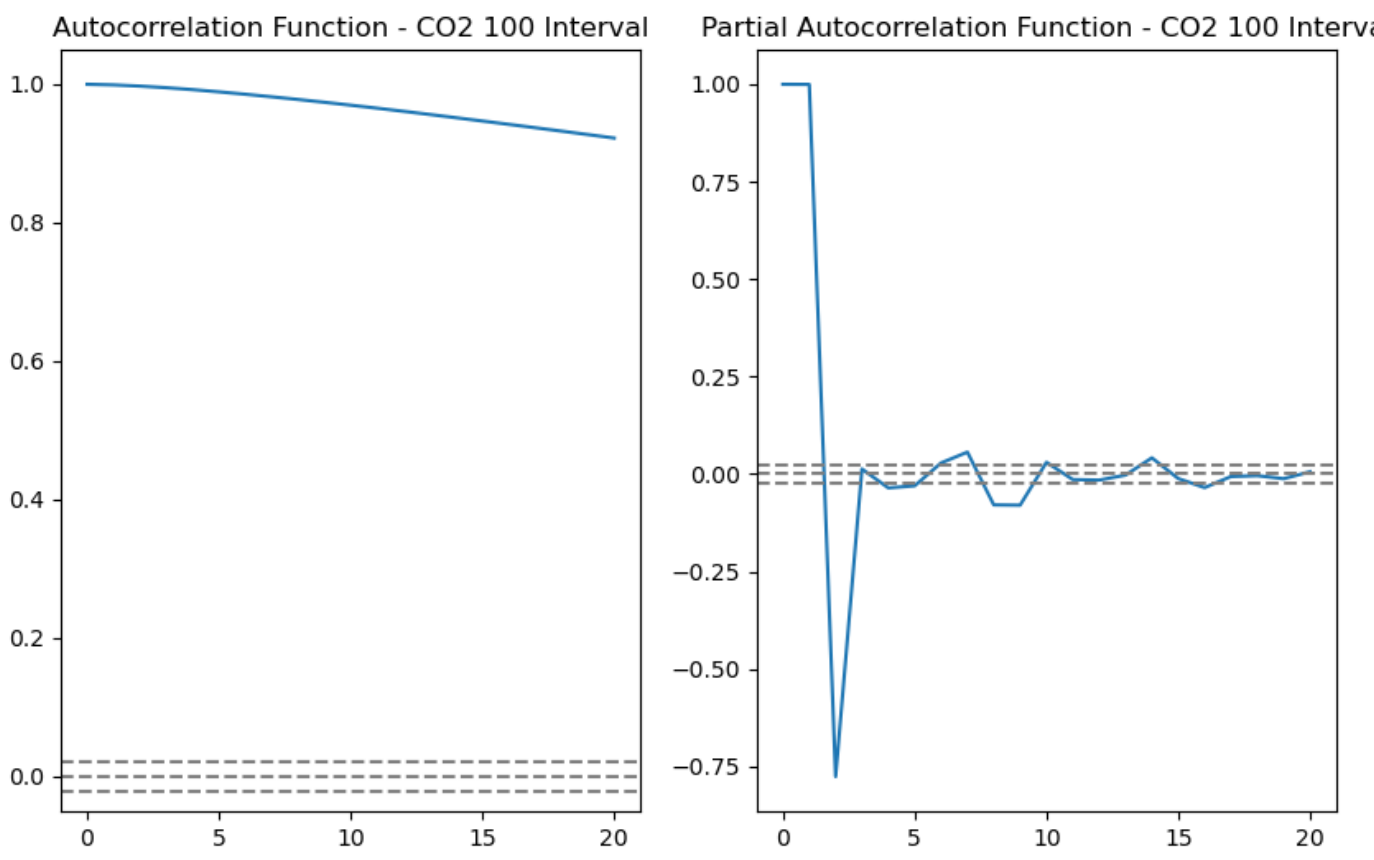


\section{CO2 1000Y}
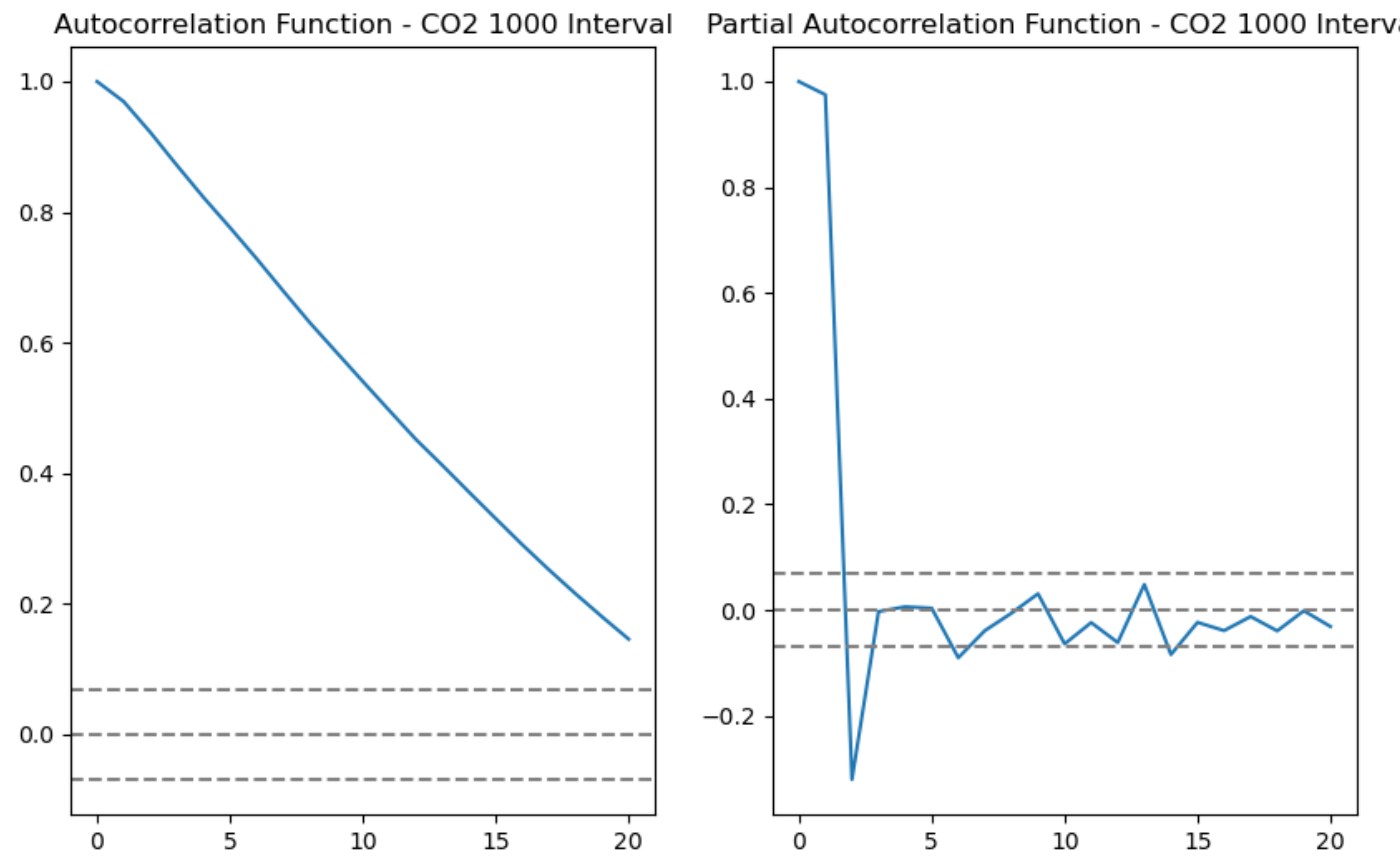


\section{Dust 100Y}
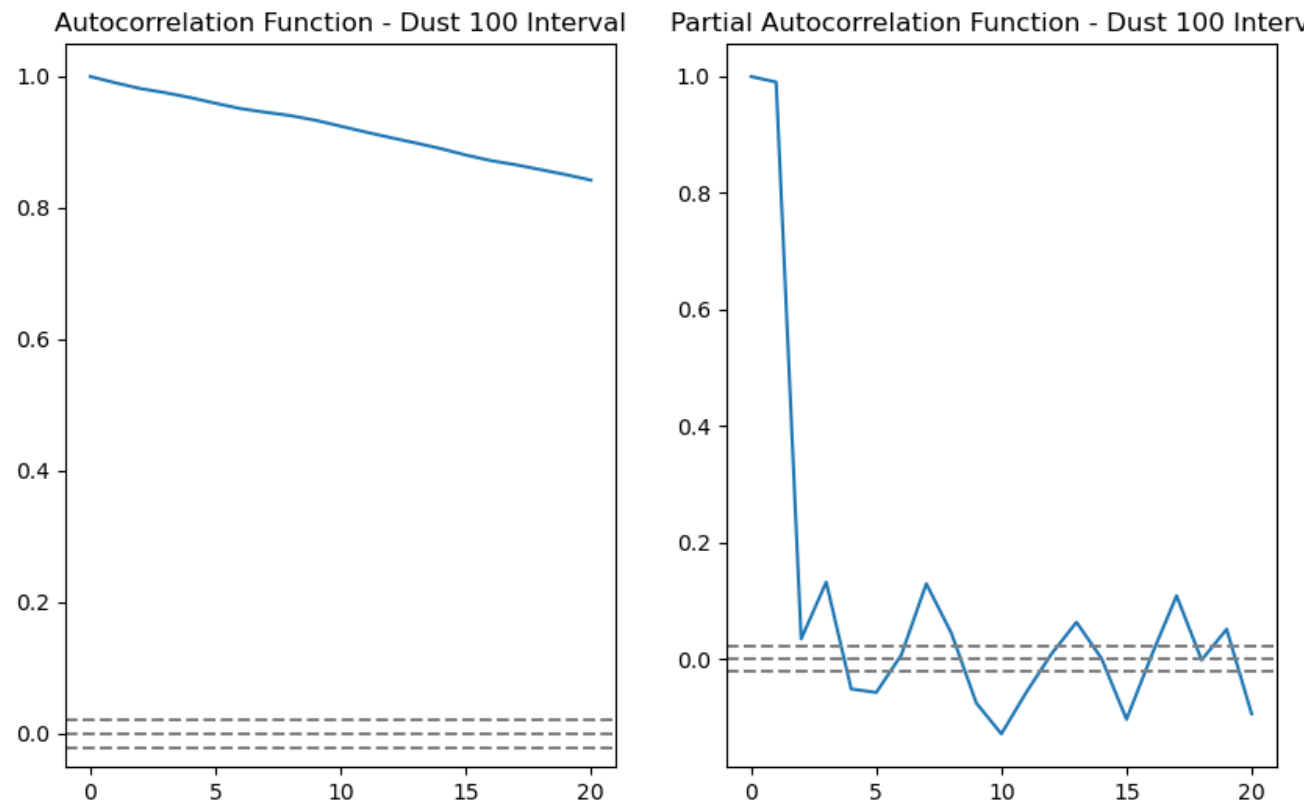

\section{Dust 1000Y}
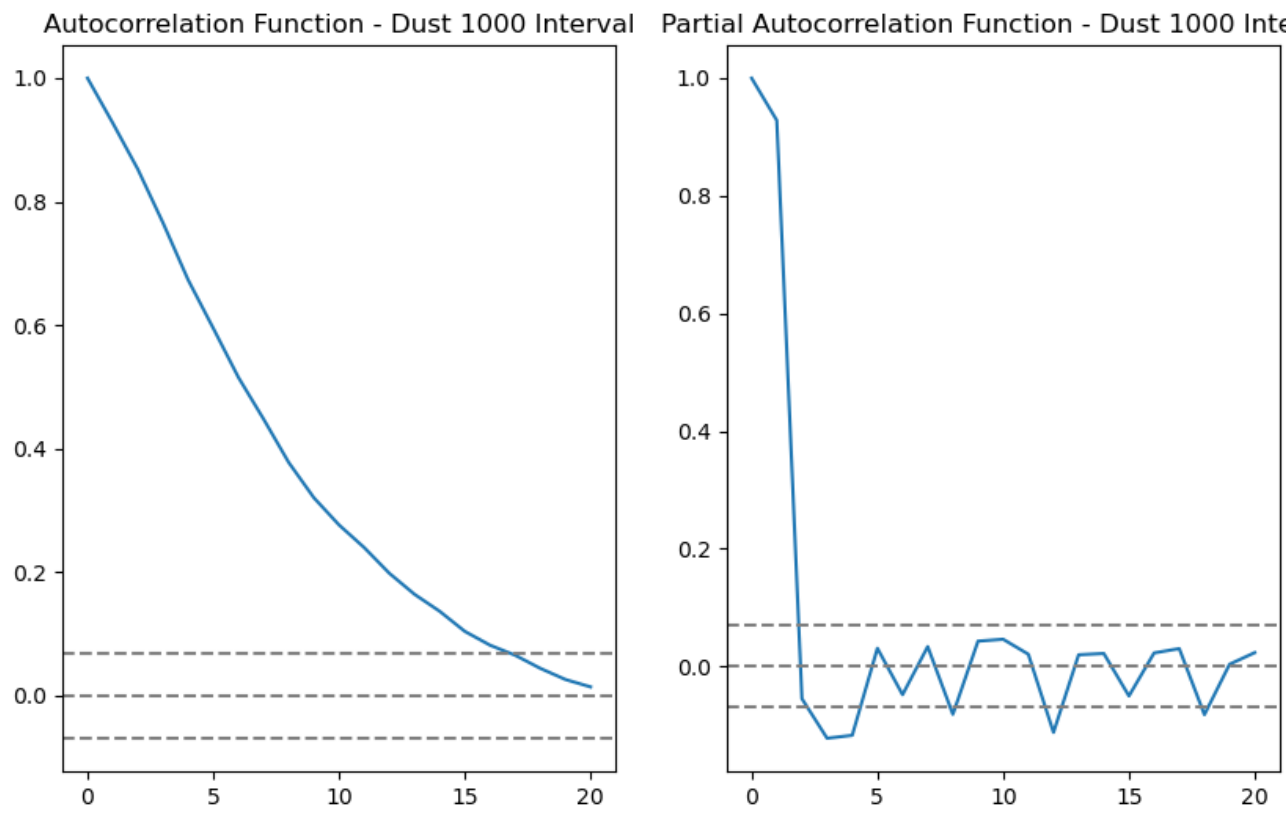